\title{
Ultrasound-Guided Transesophageal Endoscopic Fine-Needle Aspiration
}

National Cancer Institute

\section{Source}

National Cancer Institute. Ultrasound-Guided Transesophageal Endoscopic Fine-Needle Aspiration. NCl Thesaurus. Code C112517.

The use of endoscopic ultrasound imaging for real-time guidance of transesophageal fine-needle aspiration. 